\title{
EFFECTS OF THE 65 MPH SPEED LIMIT ON INJURY MORBIDITY AND MORTALITY*
}

\author{
Alexander C. WAGENAAR \\ Division of Epidemiology, School of Public Health, University of Minnesota, \\ Minneapolis, MN 55455, U.S.A.
}

and

Frederic M. STREFF and Robert H. SCHULTZ

The Transportation Research Institute, University of Michigan, Ann Arbor, MI 48109, U.S.A.

(Received 12 December 1989; in revised form 1 March 1990)

\begin{abstract}
Effective December 1987 and January 1988, the maximum speed limit on rural limited access highways in Michigan was raised from $55 \mathrm{mph}$ to $65 \mathrm{mph}$. This study examined the effects of the raised limit on injury morbidity and mortality. A multiple time-series design was used, comparing roads where the specd limit was raiscd with roads where the limit remained unchanged. Data were collected on numbers and rates of automobile crashes, injuries, and deaths from January 1978 through December 1988. Time-series intervention analyses were conducted to estimate effects associated with the speed limit change while controlling for long-term trends, seasonal cycles, and other patterns. Statistical controls were also included for major factors known to influence crash and injury rates. Results revealed significant increases in casualties on roads where the speed limit was raised, including a $19.2 \%$ increase in fatalities, a $39.8 \%$ increase in serious injuries, and a $25.4 \%$ increase in moderate injuries. Fatalities also increased on 55 mph limited access freeways, suggesting that the $65 \mathrm{mph}$ limit may have spillover effects on segments of freeways where the limit was not changed. No significant changes in fatalities or injuries were found on other types of roads. The increased convenience of reduced travel time with the higher speed limit is obtained at a significant cost in terms of injury morbidity and mortality.
\end{abstract}

We measured the effects on morbidity and mortality due to motor vehicle crashes of raising the maximum speed limit from $55 \mathrm{mph}$ to $65 \mathrm{mph}$ on Michigan's rural interstate highways and other rural highways built to interstate standards. In April 1987, U.S. Senate Bill HR-2 was passed permitting states to raise the maximum speed limit to 65 mph on rural interstates. Michigan's governor signed Public Act 154 of 1987 on October 29,1987 , increasing speed limits on segments of Michigan's rural interstate highways from 55 to $65 \mathrm{mph}$, with no change in the minimum allowable speed of $45 \mathrm{mph}$. New speed limit signs were in place and the speed limit was officially increased to $65 \mathrm{mph}$ on Michigan's rural interstate system on November 27, 1987. Furthermore, as a part of the massive budget reconciliation package passed in late December 1987, the U.S. Congress authorized a four-year demonstration project in which 20 states were permitted to increase maximum speed limits from 55 to $65 \mathrm{mph}$ on noninterstate highways built to interstate standards. Michigan chose to participate in the demonstration project, and 65 mph speed limit signs were in place and the new limit was in force on all affected sections of rural noninterstate highways by the end of January 1988 .

There are two major dimensions of the expected effects of the speed limit on crash involvement: average speed and variance in speeds. Higher speeds produce greater impact forces in crashes, increasing the probability of serious injury or death. Assuming that a vehicle strikes a fixed, unmoving object (such as a bridge abutment), the kinetic energy of the occupants must be dissipated in a fraction of a second. If vehicle occupants are not wearing safety belts, this energy will be dissipated by the body against the windshield, dashboard, steering column, or against a seat-back. Since the kinetic energy increases with the square of the speed, increased speed disproportionately increases the

*This study was conducted while the senior author was at the University of Michigan Transportation Research Institute. 
probability that occupants are injured. According to estimates of Giamotty and associates (1980), a crash with an impact speed of $40 \mathrm{mph}$ is twice as likely to result in serious injury (overall AIS greater than 2) than a crash with an impact speed of $30 \mathrm{mph}$. In short, if raising the speed limit to $65 \mathrm{mph}$ increases average speeds on the road, the average speed at impact in traffic crashes would likely increase, with a consequent increase in probability of serious injury or death resulting from those crashes. In addition, higher speeds reduce the time available for drivers to execute avoidance maneuvers, potentially increasing the number of crashes.

A second potential effect of raising the speed limit is increased speed variance. Speed variance refers to the distribution of speeds present on a given road in a given area. That is, how many cars are going faster or slower than the average speed? An increase in the proportion of vehicles on the road that are traveling significantly slower or faster than the average speed increases the probability of traffic crashes (Lave 1985; Garber and Gadirau 1988). Conversely, having all vehicles traveling at the same speed reduces the probability of traffic crashes. The role of changing the speed limit on speed variance is not fully understood. There is a general statistical phenomenon that the variance of a measure increases as the mean increases. Based on this common pattern, an increase in average speed resulting from raising the speed limit would also be expected to increase the variance in speeds. This is intuitively reasonable, since some drivers, who prefer driving at $55 \mathrm{mph}$, will continue to do so after the limit is raised. Other drivers will take advantage of the raised limit to increase their speeds. The result is increased speed variance, which is likely to increase the number of crashes. In short, if the $65 \mathrm{mph}$ limit increases speed variance, a possible result is an increased number of traffic crashes, causing an increase in the number of motorists killed or injured.

Design speed may also influence how the speed limit change affects speed variance. Design speed is "the maximum safe speed that can be maintained over a specified section of highway when conditions are favorable such that the design features of the highway govern" (Garber and Gadirau 1988). Garber and Gadirau found that speed variance increased as the difference between the posted speed limit and the design speed of the road segment increased. Perhaps this is because drivers tend to increase their driving speed as the geometric characteristics of the roadway improve, regardless of the posted speed limit. Speed variance was found to be at a minimum on road segments where the posted speed limit was 6 to $12 \mathrm{mph}$ below the design speed. If this pattern holds true across jurisdictions and across time, raising the speed limit would not increase speed variance as much as otherwise expected, and would not have as deleterious effects on injury morbidity and mortality as expected. To help isolate the effects of the raised speed limit, average speed and speed variance, we examined both numbers of traffic crashes and levels of injury severity. But we did not collect detailed information on design speed and speed variance by road segment. Therefore, our results show the effects of the raised limit on injury outcomes, but do not fully resolve questions regarding the relative contribution of changes in average speed or speed variance to observed increases in morbidity and mortality.

Several studies of the effect of the recent United States policy change permitting states to raise the speed limit from 55 to $65 \mathrm{mph}$ have appeared. These reports indicate the following effects on roads with raised speed limits: $20 \%$ increase in fatal and seriousinjury crashes in Texas (Brackett and Pendleton 1988), 18\% increase in crashes in Alabama (Brown et al. 1989), 93\% increase in the fatal crash rate in New Mexico (Gallaher et al. 1989), 15\% aggregate increase in fatalities in 38 states that raised the limit (Baum et al. 1989), 14\% aggregate increase in fatalities in 38 states that raised the limit (National Highway Traffic Safety Administration 1989), 15\% aggregate increase in fatalities in 40 states that raised the limit (Garber and Graham 1990), and 27\% aggregate increase in fatalities in 20 states that raised the limit (McKnight et al. 1989). Results are not consistent across states, and some of these findings are based on suspect analytic methods, such as use of chi-squared tests and analysis of variance techniques on serially correlated time-series data. 
METHODS

\section{Research design}

Alternate explanations for observed changes in morbidity and mortality at the time of the speed limit change were controlled in three ways. First, a monthly time-series design was used to control for multi-year trends, seasonal cycles, and other regular patterns in the outcome variables. Measurement of a significant change beginning in the exact month the speed limit was raised strengthens the argument that observed differences were due to changes in speed limit.

Second, the time-series statistical models included several covariates, such as vehicle miles traveled, unemployment, and alcohol consumption, to control for their effects on deaths, injuries, and property damage. Inclusion of covariates in the time-series models further increase confidence that observed differences are a result of changes in speed limit. In addition, effects of other major policy changes known to influence injury rates, such as a compulsory safety belt law, were statistically controlled.

Third, multiple comparison time series were used to increase confidence that the raised speed limit is responsible for observed changes in morbidity and mortality. Comparisons were made between specific road segments where the speed limit was raised and roads where the limit remained unchanged. Specifically, we compared changes in the outcome measures for road segments where the limit was raised to $65 \mathrm{mph}$ with (1) limited access highway road segments where the limit remained at $55 \mathrm{mph}$ and (2) all other roads, where existing speed limits remained unchanged. The primary effects of the new $65 \mathrm{mph}$ limit were expected only on those segments with the higher limit. While there may be some spillover effects on other road segments where the speed limit remained unchanged, any such spillover effects were expected to be small compared to the primary effects.

\section{Data collection}

Data on motor vehicle crashes from January 1978 through December 1988 were obtained from the Michigan State Police. Records were available on all traffic crashes occurring in Michigan reported to any state, county, or municipal police agency. Cases included in all time series were filtered to exclude motor vehicle crashes involving pedestrians and/or pedalcycles, since the raised speed limit is unlikely to affect the behavior of pedestrians and pedalcyclists. Each crash and injury record was stratified by whether the crash occurred on a section of limited-access highway currently posted at $65 \mathrm{mph}$, a section of limited-access highway where the speed limit remained $55 \mathrm{mph}$, or another class of road. Furthermore, we stratified outcome measures by crash configuration (single-vehicle, car-car, car-truck), vehicle damage level, and gender, age, and injury severity of crash victims. *

Covariates used in the monthly time-series models include implementation of an adult safety belt law in July 1985, estimated number of vehicle miles traveled in the state, proportion of licensed drivers under age 25, aggregate beer consumption in the state, and percentage of the labor force unemployed. Data on vehicle miles traveled and the number of licensed drivers by age and gender were obtained from the Federal Highway Administration. Monthly wholesale beer distribution figures were obtained from the U.S. Beer Institute. Data on percentage of the labor force unemployed were obtained from the Michigan Department of Management and Budget.

Finally, quarterly data on measured speeds of vehicles on the road were obtained from the Michigan Department of Transportation for the 1982-1988 period. Data are collected with pneumatic tube speed measuring devices at some locations and permanent magnetic speed loops imbedded in the pavement at other locations. Speeds are sampled 
at 44 sites each year.* Approximately one-third of these sites are sampled quarterly, with the remaining sampled annually. We identified the location of each sample site and the current posted speed limit at each site to assess changes in driving speeds on the road segments where the limit was raised to $65 \mathrm{mph}$.

\section{Statistical analyses}

The goal of the time-series analyses was to estimate changes in the frequency of crashes, injuries, and deaths associated with raising speed limits from 55 to $65 \mathrm{mph}$. Box-Jenkins and Box-Tiao methods were employed to control for long-term trends and seasonal cycles, and to estimate changes beginning the first month the increased speed limit took effect (Box and Jenkins 1976; Box and Tiao 1975). The Box-Jenkins approach is a versatile time-series modeling strategy that can model a wide variety of trend, seasonal, and other recurring patterns.

At a conceptual level, the analytic strategy involves explaining as much of the variance in each variable as possible on the basis of its past history, before attributing any of the variance to another variable, such as the increased speed limit. The intervention-analysis approach is particularly appropriate for this study, because the objective was to identify significant changes in injury morbidity and mortality associated with the increased speed limit, independent of observed regularities in the history of each variable. Controlling for baseline trends and cycles with time-series models avoids biased standard error estimates that typically result from the use of conventional statistical procedures on time-series data, violating assumptions of independence.

After controlling for long-term trends, cycles, and other regularities with ARIMA models, we added an intervention step function for the month the speed limit was raised, to estimate the associated change in each outcome variable. We added a second intervention function to the time-series models to estimate the anticipatory effect of the policy change. Considerable debate and media coverage of the speed limit issue occurred throughout 1987, as bills were introduced, passed, and signed at the federal and state level. The resulting publicity may have resulted in a small portion of the law's effects occurring before the law actually took effect. To determine whether this was the case, we constructed a second intervention variable a priori, based on knowledge of publicity concerning the speed limit. The anticipatory effect variable had the value zero from January 1978 through December 1986 (Fig. 1). It incremented .01 per month from January through March 1987, because of publicity surrounding discussions of possible speed limit increase legislation. An additional increment of .31 was added in April to account for the sudden increase in publicity associated with the April congressional override of the president's veto of the bill raising the speed limit. An additional .02 per month increment was added for May through September, representing the Michigan discussion and debate of a proposed increase in speed limit. An increment of .52 was added in October 1987, the month Governor Blanchard signed the bill raising the speed limit. Finally, an increment of .04 was added for November 1987, such that all monthly increments summed to 1.0 .

A number of covariates were included in the time-series models to account for changes in casualties due to other factors. Covariates included Michigan's compulsory safety belt use law, aggregate vehicle miles traveled, proportion of the licensed driver population under age 25 , beer consumption, and unemployment. These variables are potential confounding factors because of established associations with traffic crash involvement. The safety belt law significantly reduced injury rates in Michigan (Streff et al. 1990). Aggregate vehicle miles traveled is a major index of exposure to risk of injury (Jovanis and Chang 1986). The proportion of young drivers influences injury rates because of the overrepresentation of young drivers in traffic crashes (Wagenaar 1983). A measure of alcohol consumption was included because of the substantial proportion of crashes that involve alcohol-impaired drivers (National Highway Traffic Safety Admin-

*Data on measured travel speeds are classified missing for the first quarter of 1986 and the first quarter of 1987 due to problems with the monitoring equipment. 


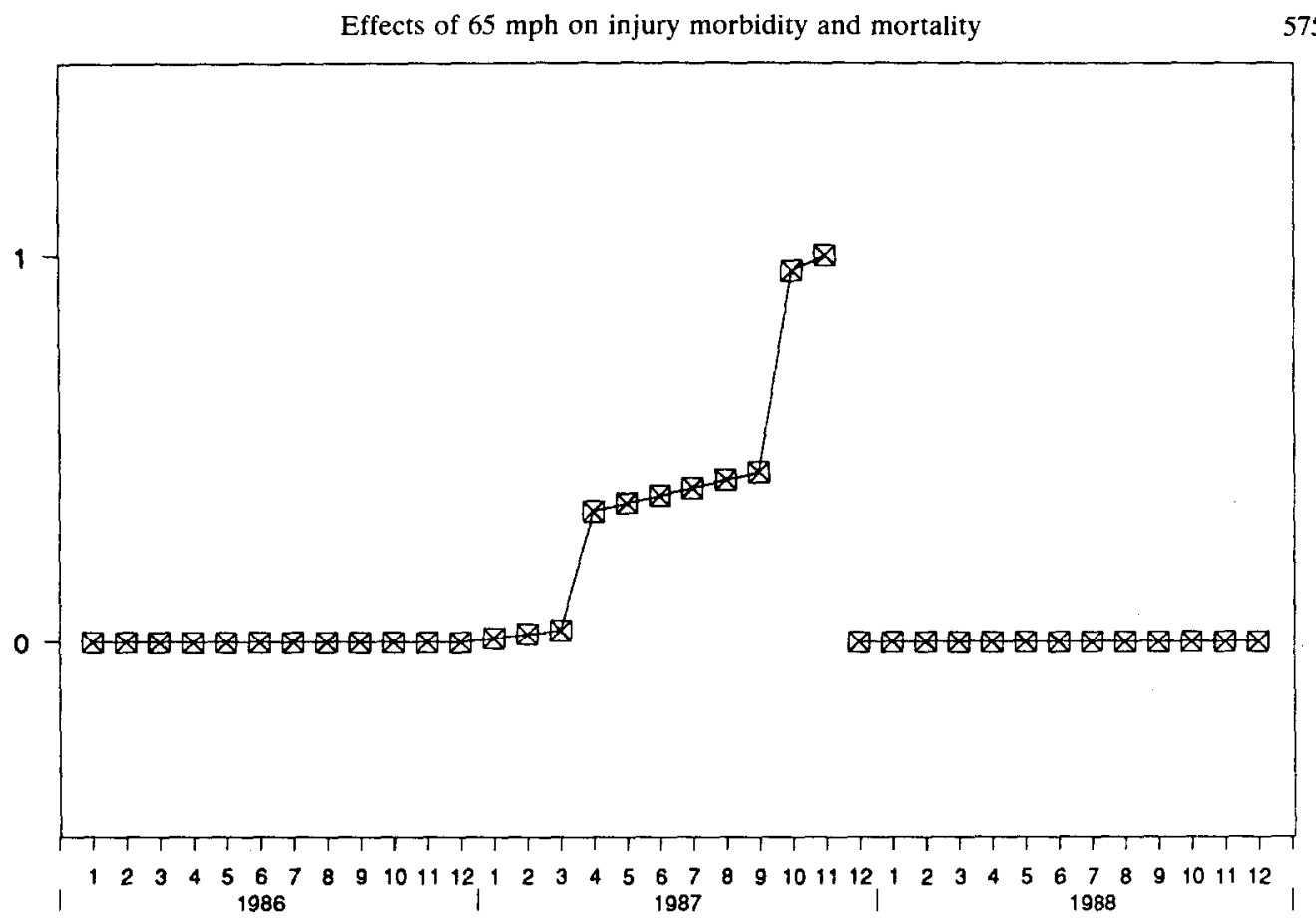

Fig. 1. Functional form of anticipatory effect variable.

istration 1988). Wholesale beer distribution was selected as the measure of alcohol consumption in preference to total absolute alcohol from all beverages (beer, wine, and distilled spirits) because the majority of impaired drivers are impaired as a result of beer consumption (Berger and Snortum 1985). Furthermore, previous research has documented the relationship between wholesale beer distribution and the number of traffic crashes (at lags of zero to two months) (Wagenaar 1984a). Finally, the unemployment

Table 1. Effects of increase in maximum speed limit: Results from time-series models with anticipatory and implementation effects

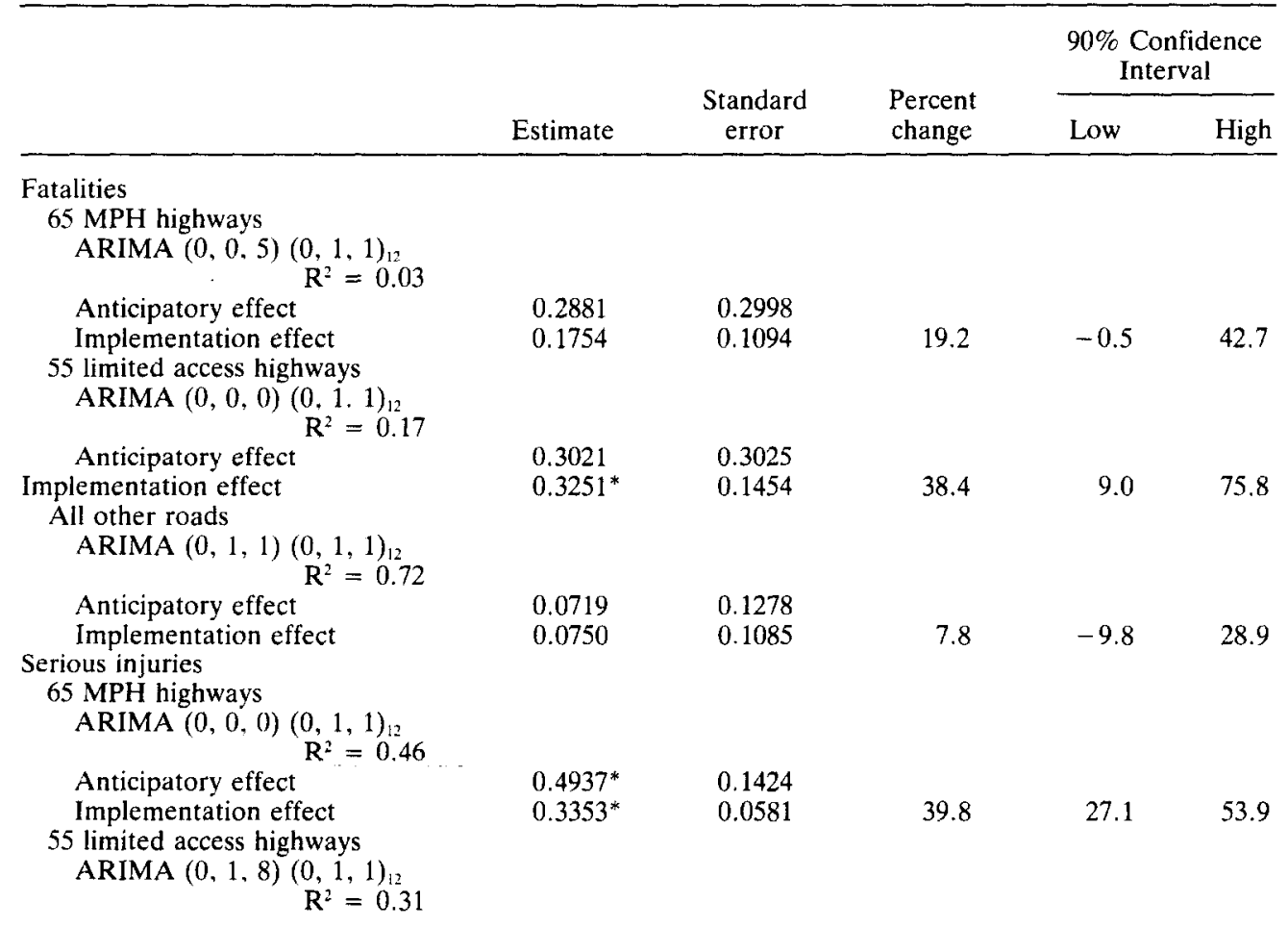


Table 1. (Continued)

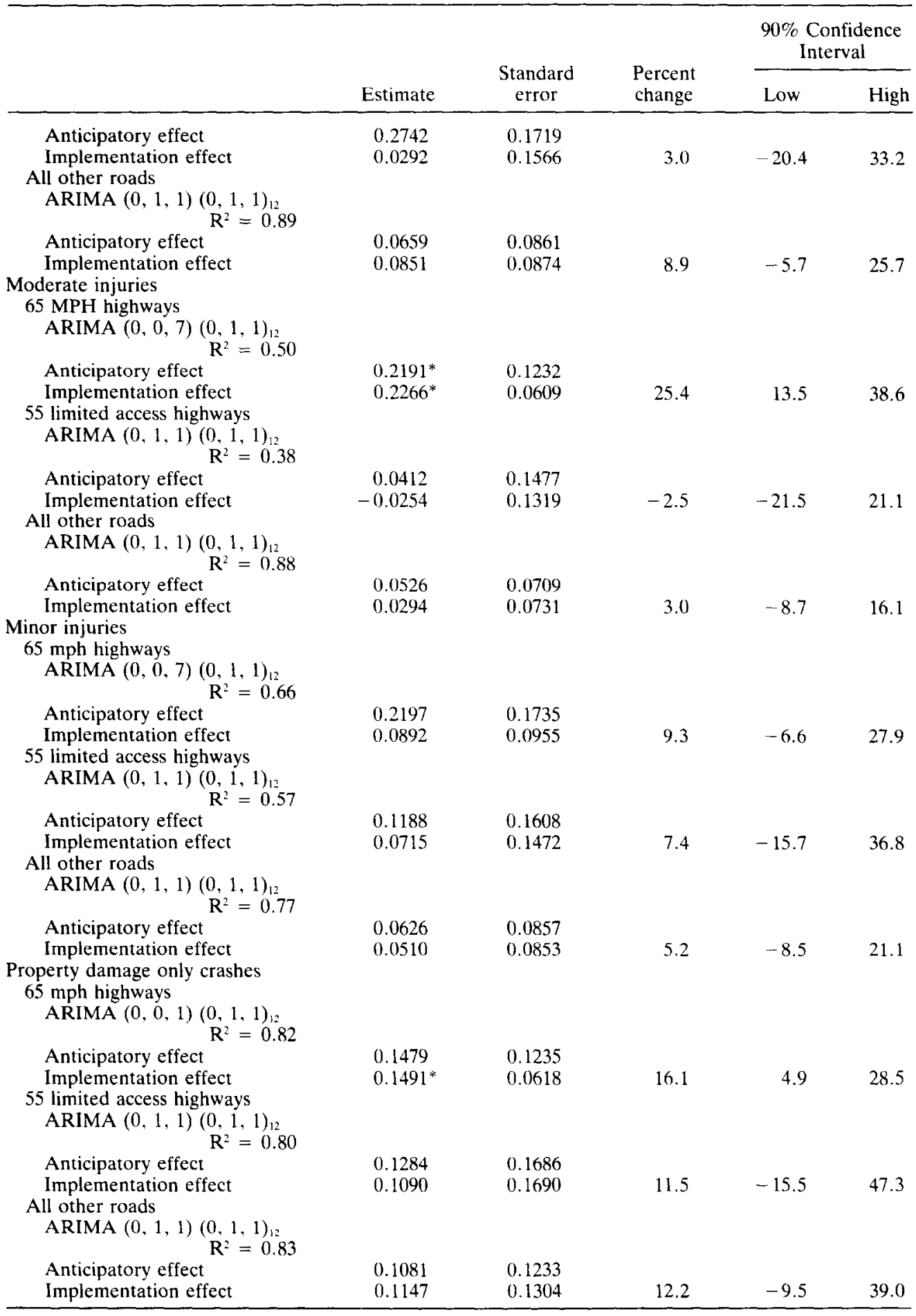

${ }^{*}$ Statistically significant at $p<.05$, one-tailed test.

rate was included (with lags of zero to four months) because previous research has shown its relationship with motor vehicle crash involvement (Joksch 1984; Partyka 1984; Wagenaar 1984b; Evans and Graham 1988; Wagenaar and Streff 1989).

\section{RESULTS}

Results clearly revealed significant increases in crash-induced injuries on road segments where the maximum speed limit increased from $55 \mathrm{mph}$ to $65 \mathrm{mph}$ (Table 1, 


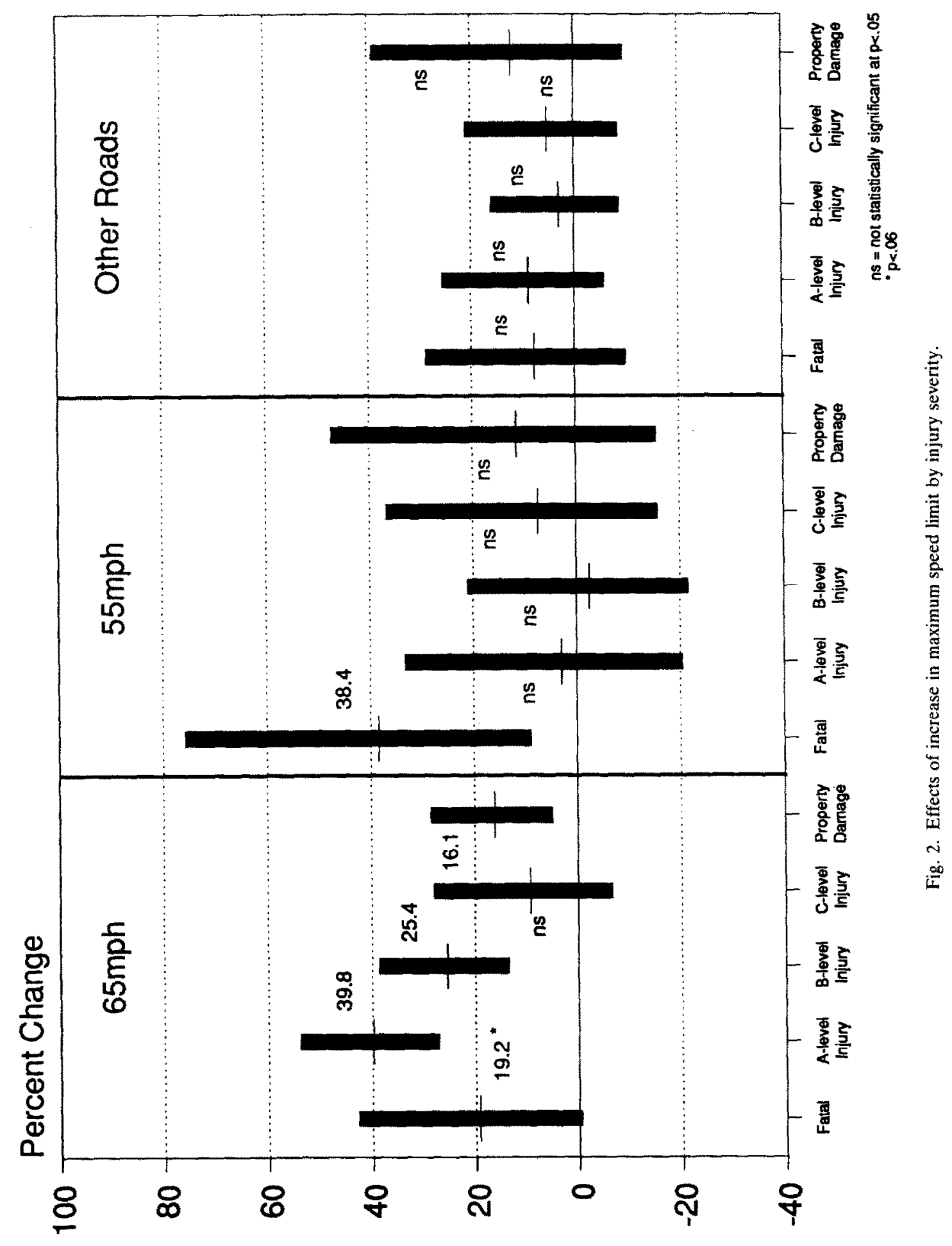




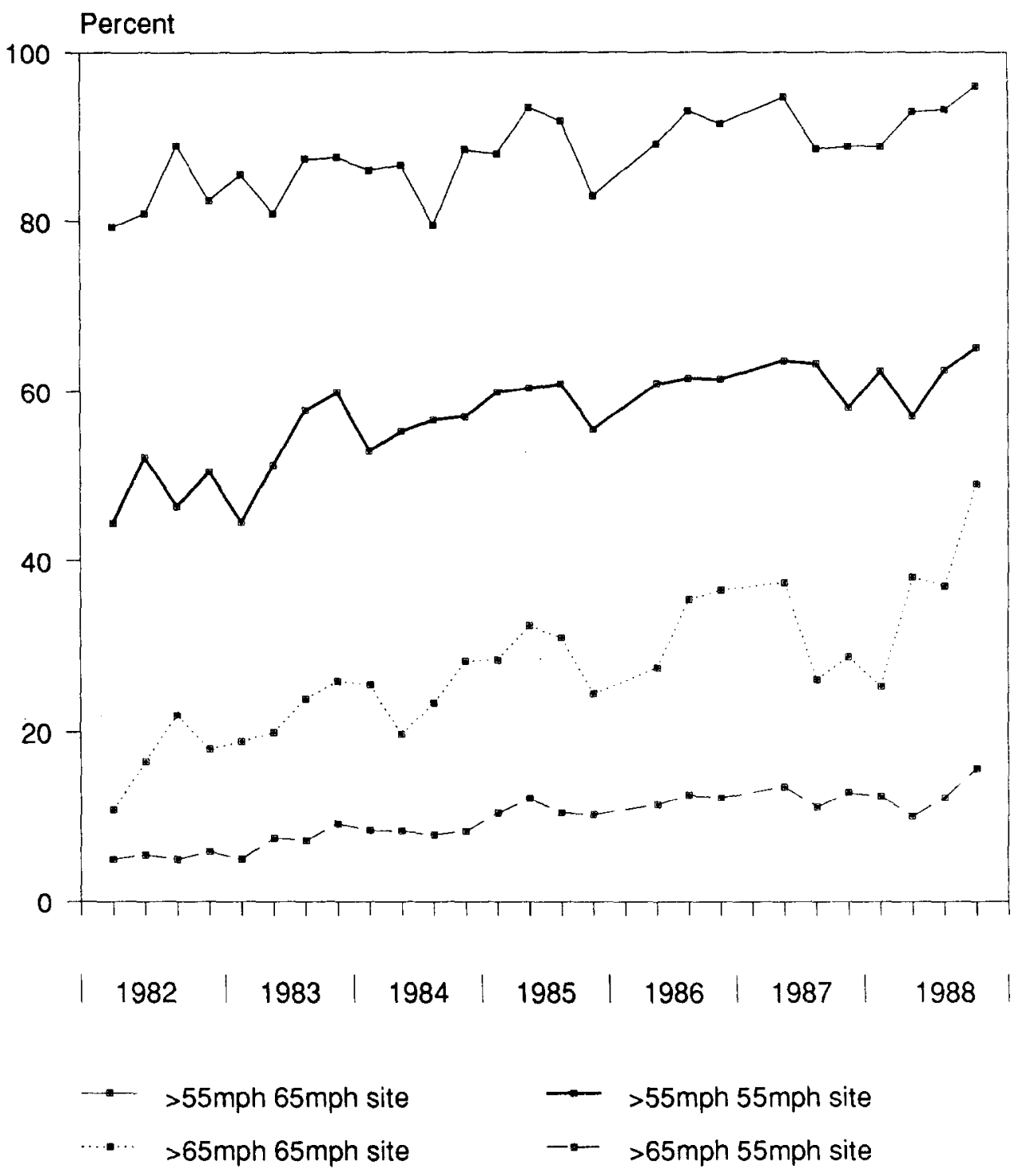

Fig. 3. Travel speeds measured at 55 sites throughout Michigan: 1982-1988.

Figure 2). Effects attributable to the increased speed limit include a $39.8 \%(p<.05)$ increase in serious (A-level) injuries and a $25.4 \%(p<.05)$ increase in moderate (Blevel) injuries on road segments with the $65 \mathrm{mph}$ limit. The number of minor (C-level) injuries did not change significantly. The number of vehicles involved in property-damage-only crashes increased $16.1 \%(p<.05)$ after the limit was increased. Finally, the number of deaths on freeways with the $65 \mathrm{mph}$ limit increased $19.2 \%(p<.06)$ and fatalities on limited access freeways posted at $55 \mathrm{mph}$ increased $38.4 \%(p<.05)$.

We believe these results reflect increased morbidity, mortality, and property damage causally attributable to the policy raising the speed limit for two reasons. First, the increases began immediately after the signs for the higher speed limit were posted. Second, with the notable exception of fatalities on limited access highways that remained at $55 \mathrm{mph}$, the increases were only found on those specific road segments where the posted speed limit was changed. However, it is important to notice the size of the confidence intervals shown in Fig. 2 and the size of the standard errors in Tables 1 through 4 . Specific pairwise comparisons between two particular road class/injury severity estimates are in most cases not statistically significant. For example, our results do not demonstrate that the raised speed limit increased A-level injuries significantly more than it increased B-level injuries. The reason for the relatively large standard errors 
Table 2. Effects of increase in maximum speed limit: Results from time-series models with implementation effect only

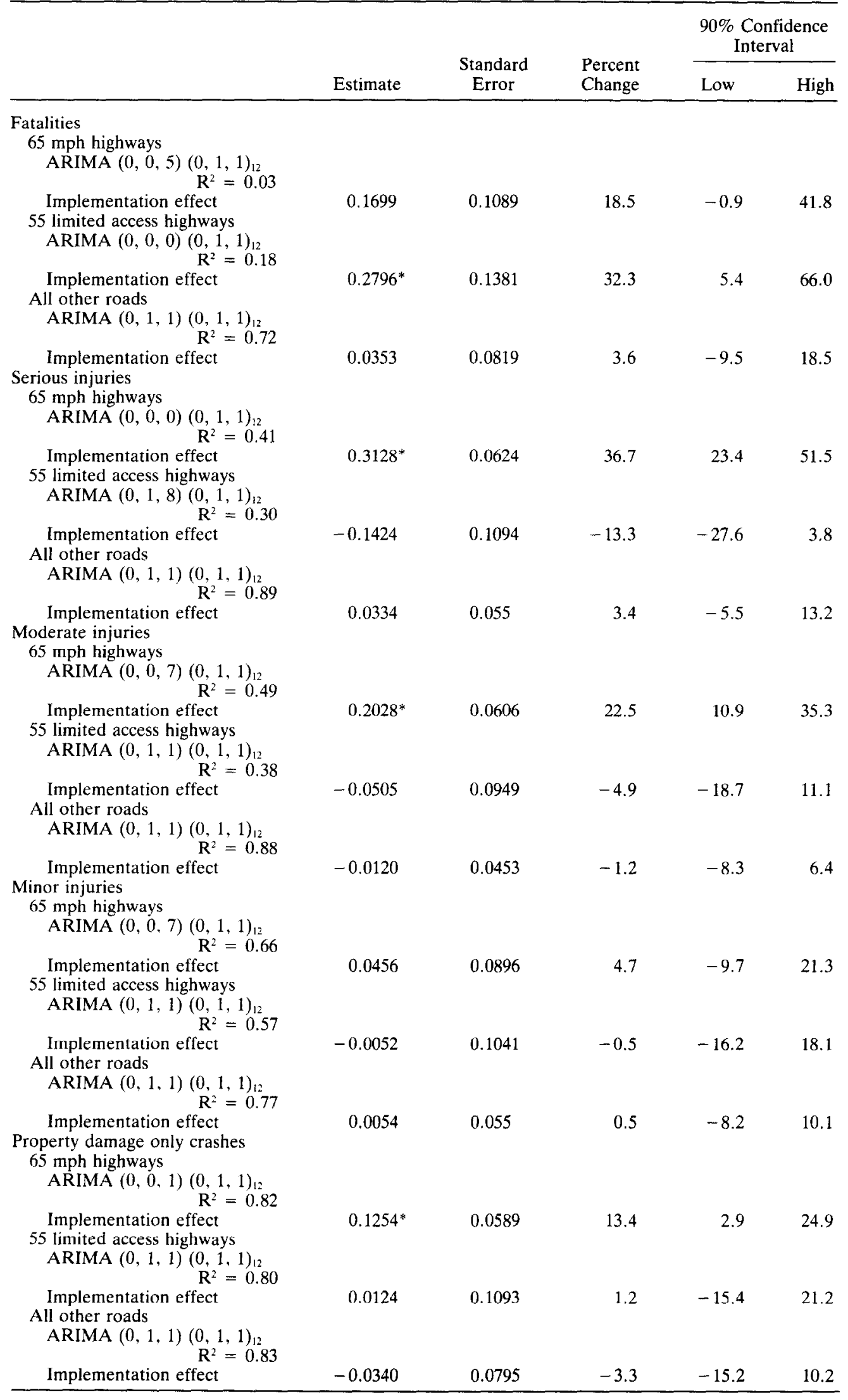

${ }^{*}$ Statistically significant at $p<.05$, one-tailed test. 
Table 3. Differential effects of increase in maximum speed limit to $65 \mathrm{mph}$ by crash configuration, vehicle damage level, gender, and age

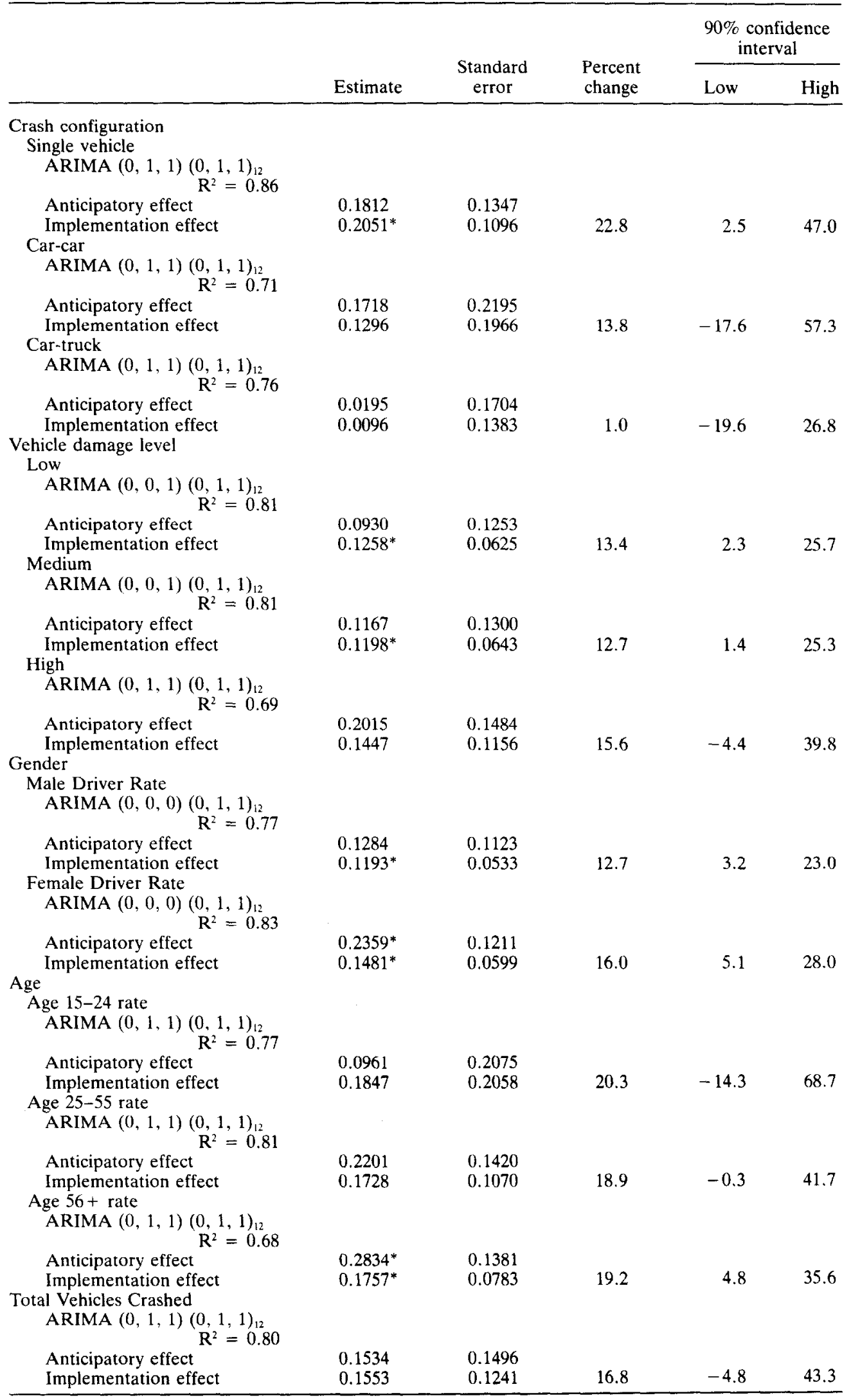

\footnotetext{
* Statistically significant at $p<.05$, one-tailed test.
} 
is the availability of only 12 months of data after the intervention. In time-series models, standard errors are the smallest (all else equal) if the intervention occurs in the middle of the series. Thus, when we have 10 years of postintervention data available, to complement the 10 years of baseline data used, we will be able to specify the differential effects of the increased speed limit with much greater precision.

We examined available data on travel speeds measured at 55 sites throughout the state of Michigan, to assess the effect of the new law on actual travel speeds. The proportion of motorists traveling over the posted speed limit has been increasing throughout the 1980s. In addition to this gradual upward trend, there was a noticeable further increase in travel speeds in 1988. This sudden increase in speeds occurred only at those sites where the limit was raised to 65 , where the proportion of motorists exceeding 65 mph increased $21.3 \%$ from 1987 to 1988 (see the dotted line in Fig. 3). Increasing travel speeds may reflect a decline in public support and police enforcement of the 55 limit in the 1980s (U.S. House of Representatives 1985).

Although the actual posting of the new $65 \mathrm{mph}$ speed limit signs occurred in late November 1987, considerable discussion and publicity regarding the pending increase in the limit occurred throughout 1987. As a result, we hypothesized that a small portion of the effect of the increased limit might have occurred before the new signs were actually posted, in anticipation of the formal change in late November and December of 1987. We tested this hypothesis by incorporating another variable in each time-series model to estimate this anticipatory effect. The anticipatory and implementation effects were then simultaneously estimated. Results revealed significant increases in serious and moderate injuries in anticipation of the speed limit change, but no significant anticipatory effects on fatalities, minor injuries, or property-damage-only crashes (Table 1). We reestimated each time-series model excluding the anticipatory effect variable to determine the effect of inclusion of this variable on the estimates of the implementation effects. Results showed virtually no differences in estimated implementation effects (Table 2). Furthermore, the models with anticipatory effects explained the same amount of variance as those without (average $R^{2}$ of models with anticipatory effect paramater was .586; average $\mathrm{R}^{2}$ of models without anticipatory effect paramater was .582).

In addition to analyses of the speed limit effects by injury severity, we assessed differential effects of the law by crash configuration, extent of vehicle damage, gender, and age (Table 3). There were no significant differences in the size of the increase in crashes associated with the $65 \mathrm{mph}$ limit across any of these groups. The increased injuries, deaths, and property damage after the $65 \mathrm{mph}$ limit took effect were experienced by both males and females.

The quasi-experimental research design, including experimental series of road segments where the speed limit was raised and comparison series of road segments where the limit remained unchanged, controlled for many threats to a causal interpretation of observed increases in casualties. To provide further confidence that other major factors influencing crash outcomes could not explain observed effects, we reestimated each timeseries model including a series of covariates that previous studies have demonstrated influence crash and injury rates. Results of models including covariates revealed larger estimated increases in fatalities, moderate injuries, and property-damage-only crashes associated with the $65 \mathrm{mph}$ speed limit than models without these covariates (Table 4). Observed increases in casualties associated with the $65 \mathrm{mph}$ speed limit cannot be attributed to other factors such as the compulsory safety belt law, changes in vehicle miles traveled, economic conditions, alcohol consumption, or changing demographics of the driver population. If anything, estimated effects without statistical controls for these factors understate the deleterious effects of the $65 \mathrm{mph}$ limit on casualty outcomes.

\section{DISCUSSION}

Raising the speed limit to $65 \mathrm{mph}$ was followed by increased casualties due to motor vehicle crashes. On road segments where the limit was raised, the percentage increases in injury and death were large (16\% to $40 \%)$. Fortunately, the limited access highways 
Table 4. Effects of increase in maximum speed limit: Results from time-series models with anticipatory effects, implementation effects, and controls for effects of covariates

\begin{tabular}{|c|c|c|c|c|c|c|}
\hline & & \multirow[b]{2}{*}{ Estimate } & \multirow[b]{2}{*}{$\begin{array}{l}\text { Standard } \\
\text { error }\end{array}$} & \multirow{2}{*}{$\begin{array}{l}\text { Percent } \\
\text { change }\end{array}$} & \multicolumn{2}{|c|}{$\begin{array}{l}90 \% \text { confidence } \\
\text { interval }\end{array}$} \\
\hline & & & & & Low & High \\
\hline \multicolumn{7}{|l|}{ Fatalities } \\
\hline \multicolumn{7}{|c|}{$65 \mathrm{mph}$ highways } \\
\hline \multicolumn{7}{|c|}{$\begin{array}{r}\operatorname{ARIMA}(0,0,5)(0,1,1)_{12} \\
\mathrm{R}^{2}=0.10\end{array}$} \\
\hline \multicolumn{2}{|c|}{ Anticipatory effect } & 0.8352 & 0.3741 & & & \\
\hline \multirow{2}{*}{\multicolumn{2}{|c|}{$\begin{array}{l}\text { Implementation effect } \\
\text { Adult belt law }\end{array}$}} & 0.3945 & 0.1705 & 48.4 & 12.1 & 96.4 \\
\hline & & -0.4901 & 0.1616 & & & \\
\hline \multicolumn{2}{|c|}{ Vehicle miles traveled } & 0.7413 & 0.9104 & & & \\
\hline \multirow[t]{5}{*}{ Unemployment rate } & Lag 0 & 0.2749 & 0.5107 & & & \\
\hline & Lag 1 & 0.3071 & 0.6364 & & & \\
\hline & Lag 2 & -1.0000 & 0.6620 & & & \\
\hline & Lag 3 & -0.2650 & 0.6421 & & & \\
\hline & $\operatorname{Lag} 4$ & 0.3383 & 0.5038 & & & \\
\hline \multirow[t]{3}{*}{ Beer consumption } & Lag 0 & 0.0966 & 0.8253 & & & \\
\hline & Lag 1 & -0.0029 & 0.8134 & & & \\
\hline & Lag 2 & 1.4340 & 0.8122 & & & \\
\hline \multicolumn{2}{|l|}{ Percent young drivers } & -0.9469 & 0.5509 & & & \\
\hline Serious injuries & & & & & & \\
\hline $65 \mathrm{mph}$ highways & & & & & & \\
\hline ARIMA $(0,0,0) \underset{\mathrm{R}^{2}}{(0,1}$ & $\begin{array}{l}, 1)_{12} \\
=0.49\end{array}$ & & & & & \\
\hline Anticipatory effect & & 0.4322 & 0.1809 & & & \\
\hline Implementation effect & & 0.2764 & 0.0887 & 31.8 & 13.9 & 52.5 \\
\hline Adult belt law & & -0.0175 & 0.0799 & & & \\
\hline Vehicle miles traveled & & 0.2014 & 0.3846 & & & \\
\hline Unemployment rate & Lag 0 & -0.3372 & 0.2376 & & & \\
\hline & Lag 1 & -0.0474 & 0.3075 & & & \\
\hline & Lag 2 & 0.1673 & 0.3289 & & & \\
\hline & Lag 3 & 0.1748 & 0.3191 & & & \\
\hline & Lag 4 & -0.1384 & 0.2453 & & & \\
\hline Beer consumption & Lag 0 & 0.8060 & 0.3765 & & & \\
\hline & Lag 1 & 0.2168 & 0.3742 & & & \\
\hline & $\operatorname{Lag} 2$ & -0.5671 & 0.3730 & & & \\
\hline Percent young drivers & & -0.3883 & 0.2895 & & & \\
\hline Moderate injuries & & & & & & \\
\hline $65 \mathrm{mph}$ highways & & & & & & \\
\hline $\operatorname{ARIMA}(0,0,0) \underset{\mathrm{R}^{2}}{(0,1}$ & $\begin{array}{l}1)_{12} \\
=0.51\end{array}$ & & & & & \\
\hline Anticipatory effect & & 0.2839 & 0.1525 & & & \\
\hline Implementation effect & & 0.2647 & 0.0848 & 30.3 & 13.3 & 49.8 \\
\hline Adult belt law & & 0.0393 & 0.0712 & & & \\
\hline Vehicle miles traveled & & -0.2752 & 0.3247 & & & \\
\hline Unemployment rate & $\operatorname{Lag} 0$ & 0.1035 & 0.2045 & & & \\
\hline & Lag 1 & -0.0307 & 0.2655 & & & \\
\hline & Lag 2 & 0.0272 & 0.2811 & & & \\
\hline & Lag 3 & 0.0174 & 0.2819 & & & \\
\hline & Lag 4 & -0.2512 & 0.2163 & & & \\
\hline Beer consumption & Lag 0 & 0.2253 & 0.3205 & & & \\
\hline & Lag 1 & 0.2186 & 0.3186 & & & \\
\hline & Lag 2 & 0.1899 & 0.3099 & & & \\
\hline Percent young drivers & & -0.5948 & 0.2622 & & & \\
\hline Minor injuries & & & & & & \\
\hline $65 \mathrm{mph}$ highways & & & & & & \\
\hline ARIMA $(0,0,0) \underset{\mathrm{R}^{2}}{(0,}$ & $\begin{array}{l}, 1)_{12} \\
=0.67\end{array}$ & & & & & \\
\hline Anticipatory effect & & 0.3374 & 0.2404 & & & \\
\hline Implementation effect & & 0.1802 & 0.1516 & 19.7 & -6.7 & 53.7 \\
\hline Adult belt law & & 0.0468 & 0.1185 & & & \\
\hline Vehicle miles traveled & & -0.8417 & 0.4090 & & & \\
\hline Unemployment rate & Lag 0 & 0.0257 & 0.2251 & & & \\
\hline & Lag 1 & -0.0200 & 0.2626 & & & \\
\hline & Lag 2 & -0.2387 & 0.2795 & & & \\
\hline & Lag 3 & 0.3863 & 0.2741 & & & \\
\hline & $\operatorname{Lag} 4$ & -0.3669 & 0.2403 & & & \\
\hline Beer consumption & $\operatorname{Lag} 0$ & 0.0547 & 0.3559 & & & \\
\hline & Lag 1 & 0.7039 & 0.3515 & & & \\
\hline & Lag 2 & 0.0163 & 0.3453 & & & \\
\hline Percent young drivers & & 0.5313 & 0.4365 & & & \\
\hline
\end{tabular}


Table 4. (Continued)

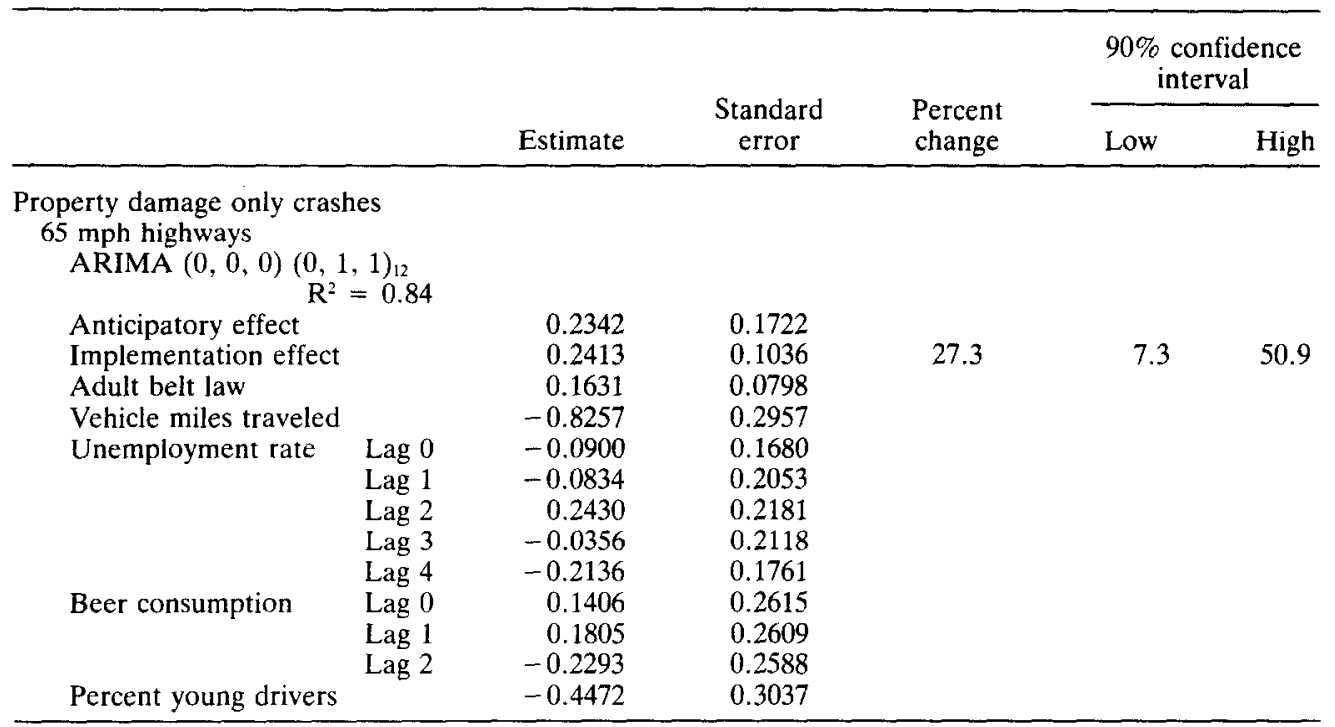

where the limit was raised are relatively safe, compared to other roads in the state. Because limited access highways have relatively low injury and death rates, the proportional increase in casualties on these roads represents a smaller increase in the actual number of people killed or injured than would occur if the limit were raised on other types of roads. Nevertheless, our results show that 27 additional people were killed, 222 experienced serious injuries, and 271 experienced moderate injuries in the first 13 months with the raised limit (Table 5). Estimated total costs in terms of the rational investment to prevent these additional injuries and fatalities is $\$ 57$ million. Similar costs to prevent property-damage-only crashes total $\$ 4.8$ million.

Many observers argue that there are also substantial benefits of the raised limit, primarily cost savings due to reduced travel time. Miller argues that the costs of the raised limit in terms of years of life lost from premature death and injury are roughly equal to the years saved from reduced travel time (Miller 1989). However, Miller also points out that the costs and benefits are not equally distributed-savings accrue to all drivers and passengers of motor vehicles, but costs are born disproportionately by those who are killed or injured in crashes. Furthermore, the risk of death or injury is not equally distributed throughout the population of motorists (young males are at higher risk, for example). It is argued by public health ethicists that equal aggregate costs and benefits of a public policy should not necessarily be considered offsetting if the distribution of the costs and benefits is unequal (Rawls 1971; Beauchamp 1976).

There are other issues that are part of the debate concerning the appropriate maximum speed limit. One might argue that there are other policies that can prevent as much or more damage than the $55 \mathrm{mph}$ limit, perhaps at lower cost or at least with a different distribution of costs. The majority of the public supports the $65 \mathrm{mph}$ limit (52\%) (Wagenaar et al. 1988), a fact used to argue for maintenance of the $65 \mathrm{mph}$ limit, or to argue for better dissemination of information regarding increased casualties caused by higher speeds. Although we found ambiguous evidence of spillover effects in this shortterm study, it is possible that higher speeds on selected (safer) road segments over the long term may gradually spread to other (less safe) road segments, increasing the deleterious effects of the raised speed limit. Furthermore, increasing the speed limit on some road segments may increase the acceptability of higher speeds by both the driving public and the law enforcement community, contributing to the "spillover" effect. Finally, raising the speed limit on some roads but not other similar roads could divert some traffic from the low-speed roads to the higher-speed roads.

Ultimately, support or opposition to the $65 \mathrm{mph}$ limit must be based on one's structure of values. Is the increased convenience of faster travel worth the increased deaths and injuries? Each individual may make his or her own decisions regarding these 
Table 5. Estimated injuries attributable to increase in speed limit to $65 \mathrm{mph}$

\begin{tabular}{lrrrr}
\hline & Actual & Expected* & Difference & \multicolumn{1}{c}{ Costs } \\
\hline Fatalities & 1,558 & 1,531 & 27 & $\$ 44,142,000$ \\
Serious injuries & 22,250 & 22,028 & 222 & $9, \mathbf{4 3 7}, 000$ \\
Moderate injuries & 43,504 & 43,233 & 271 & $\$, 544,000$ \\
Total casualties & 67,312 & 66,792 & 520 & $\$ 57,123,000$ \\
Property damage only crashes & 623,016 & 620,808 & 2,208 & $4,813,000$ \\
Total & 690,328 & 687,600 & 2,728 & $\$ 61,936,000$ \\
\hline
\end{tabular}

${ }^{*}$ Expected represents the estimated number of deaths or injuries that would have occurred in the 13-month post-law period analyzed had the speed limit not changed.

$\dagger$ Based on 1988 adjusted willingness-to-pay values of $\$ 1,634,904$ per fatality, $\$ 42,508$ per serious injury, $\$ 13,079$ per moderate injury, $\$ 2,180$ per property-damage-only crash (Federal Highway Administration 1988). Original calculated in 1986 dollars, adjusted annually by consumer price index to 1988 dollars.

trade-offs. But a safe and efficient transportation system is inherently a collective good. Therefore, collective acknowledgement and public debate on the benefits and costs of alternative speed limit policies is necessary (Beauchamp 1988). Moreover, decisions regarding appropriate speed limits must be based on the welfare of the community as a whole. Results of the current study showing increased morbidity and mortality following the raised speed limit are a central dimension of the debate.

Acknowledgement-This study was supported by the U.S. National Highway Traffic Safety Administration and the Michigan Office of Highway Safety Planning. Results and conclusions are solely those of the authors. We appreciate the helpful comments of three anonymous reviewers

\section{REFERENCES}

Baum, H. M.; Lund, A. K.; Wells, J. K. The mortality consequences of raising the speed limit to $65 \mathrm{mph}$ on rural interstates. Am. J. Pub. Health 79:1392-1395; 1989.

Beauchamp, D. Public health as social justice. Inquiry $12: 3-14 ; 1976$.

Beauchamp, D. E. The health of the Republic: Epidemics, medicine, and moralism as challenges to democracy. Philadelphia, PA: Temple University Press; 1988.

Berger, D. E.; Snortum, J. R. Alcohol beverage preferences of drinking-driving violators. J. Stud. Alcohol 46:232-239; 1985

Box, G. E. P.; Jenkins, G. M. Time series analysis: Forecasting and control. Revised edition. San Francisco, CA: Holden-Day; 1976

Box, G. E. P.; Tiao, G. C. Intervention analysis with applications to economic and environmental problems. J. Am. Stat. Assoc. 70:70-79; 1975 .

Brackett, R. Q.; Pendleton, O. J. The safety impact of the $65 \mathrm{mph}$ speed limit. College Station, TX: Texas Transportation Institute; 1988.

Brown, D. B.; Maghsoodloo, S.; McArdle, M. E. The safety impact of the $65 \mathrm{mph}$ speed limit: A case study using Alabama accident records. Auburn, AL: Auburn University; 1989.

Evans, W.; Graham, J. D. Traffic safety and the business cycle. Alcohol, drugs, and driving 4(1):31-38; 1988.

Gallaher, M. M.; Sewell, C. M.; Flint, S.; Herndon, J. L.; Graff, H.; Fenner, J.; Hull, H. F. Effects of the 65-mph speed limit on rural interstate fatalities in New Mexico. JAMA 262:2243-2245; 1989.

Garber, N. J.; Gadirau, R. Speed variance and its influence on accidents. Washington, D.C.: AAA Foundation for Traffic Safety; 1988.

Garber, S.; Graham, J. D. The effects of the new 65 Mile-Per-Hour speed limit on rural highway fatalities: a state-by-state analysis. Accid. Anal. Prev. 22:137-149; 1990.

Giamotty, P. A.; Campbcll, K. L.; Chirachavala, T.; Carsten, O.; O'Day, J. Statistical Analysis of the National Crash Severity Study Data. DOT-HS-805-561. Washington, D.C.: National Highway Traffic Safety Administration; 1980.

Joksch. H. C. The relation between motor vehicle accident deaths and economic activity. Accid. Anal. Prev. 16:207-210; 1984.

Jovanis, P. P.; Chang, H. Modeling the relationship of accidents to miles traveled. Trans. Res. Record 1068:42$51 ; 1986$

Lave, C. A. Speeding, coordination, and the $55 \mathrm{mph}$ limit. Am. Econ. Rev. 75(5):1159-1164; 1985.

McKnight, A. J.; Klein, T. M.; Tippetts, A. S. The effect of the $65 \mathrm{mph}$ limit on speeds and accidents. DOTHS-807-463. Landover, MD: National Public Services Research Institute; 1989.

Miller, T. R. $65 \mathrm{mph}$ : Winners and losers. Washington, DC: The Urban Institute; 1989.

National Highway Traffic Safety Administration. Fatal Accident Reporting System: 1987. DOT-HS-807-360. Washington, D.C.: U.S. Department of Transportation; 1988.

National Highway Traffic Safety Administration. The effects of the $65 \mathrm{mph}$ speed limit during 1987: A report to Congress January 1989. Washington, D.C.: National Highway Traffic Safety Administration; 1989.

Partyka, S. C. Simple models of fatality trends using employment and population data. Accid. Anal. Prev. 16:211-222; 1984. 
Rawls, J. A theory of justice. Cambridge, MA: Harvard University Press; 1971.

Streff, F. M.; Wagenaar, A. C.; Schultz, R. H. Reductions in police-reported injuries with Michigan's safety belt law. J. Safety Res. 21:9-18; 1990.

U.S. House of Representatives. To examine the enforcement and monitoring of the 55-mile-per-hour speed limit. hearing. Ninety-Ninth Congress, First Session, Committee on Public Works and Transportation. Washington, D.C.: Government Printing Office; 1985.

Wagenaar, A. C. Alcohol, young drivers, and traffic accidents: Effects of minimum age laws. Lexington, MA: Lexington Books; 1983.

Wagenaar, A. C. Alcohol consumption and the incidence of acute alcohol-rclated problems. Br. J. Addict. 79:173-180; 1984a.

Wagenaar, A. C. Effects of macroeconomic conditions on the incidence of motor vehicle accidents. Accid. Anal. Prev. 16:191-205; 1984b.

Wagenaar, A. C.; Molnar, L. J.; Streff, F. M.; Schultz, R. S. Michigan omnibus state safety survey: Fall 1987. Ann Arbor, MI: The University of Michigan Transportation Research Institute; 1988.

Wagenaar, A. C.; Streff, F. M. Macroeconomic conditions and alcohol-impaired driving. J. Stud. Alcohol $50(3): 217-225 ; 1989$. 